\title{
Effect of Temperature, Moisture, and Soil Texture on DCPA Degradation
}

\author{
J. S. Choi, T. W. Fermanian, * D. J. Wehner, and L. A. Spomer
}

\begin{abstract}
Turf managers sometimes experience poor or early loss of control of targeted weeds, even when herbicides are applied at recommended rates. This study was conducted to determine the influence of soil temperature and moisture on the rate of DCPA (dimethyl tetrachloroterephthalate) degradation in soil. The effect of six soil temperatures, three soil moistures, and three soil textures on the degradation of DCPA was measured in the laboratory through HPLC analysis. Soil temperature influenced the rate of DCPA degradation in the following order: $10<<15<<20<25=30>35^{\circ} \mathrm{C}$. The average half-life ranged from $92 \mathrm{~d}$ at $10^{\circ} \mathrm{C}$ to $18 \mathrm{~d}$ at $30^{\circ} \mathrm{C}$. Soil moisture content influenced the rate of degradation in the following order: low $\left(0.1 \mathrm{~kg} \mathrm{H}_{2} \mathrm{O} \mathrm{kg}^{-1}\right.$ soil $)<$ medium $\left(0.2 \mathrm{~kg} \mathrm{H}_{2} \mathrm{O} \mathrm{kg}^{-1}\right.$ soil) $=$ high $(0.4$ $\mathrm{kg} \mathrm{H}_{2} \mathrm{O} \mathrm{kg}$ ' soil). The average half-life values of DCPA were 49 , 33, and $31 \mathrm{~d}$ for the low, medium, and high soil moisture levels, respectively. A mathematical model of DCPA loss was utilized to determine the relative contribution of time, soil moisture, and soil temperature to the rate of degradation. Faster degradation of DCPA was observed from a sand/soil moisture $(47.5: 52.5, w / w)$ than from either a sand or a soil (Flanagan silt loam [fine, montmorillonitic, mesic Aquic Argiudoll]). It was concluded that the dissipation rate of DCPA is largely dependent on soil environmental conditions including soil temperature, soil moisture, soil texture, and the time interval since the application to the soil. Thus, it is suggested that soil environmental factors be considered in determining the timing of second or subsequent applications when necessary rather than following a fixed application schedule.
\end{abstract}

Additional index words: Crabgrass, Digitaria spp., Turfgrass, Preemergence herbicide, Pesticide fate.

HE CHEMICAL control of annual grasses is regarded as one of the most important procedures in turfgrass maintenance. The use of preemergence herbicides has been very effective for the short-term control of this group of weeds. To maintain a sufficient concentration of herbicide in the soil for continued control of grass weeds from early spring through mid-summer, it is necessary to apply the herbicide in concentrations above that required for initial control.

J.S. Choi, Dep. of Ornamental Horticulture, Dankuk Univ., Korea; T.W. Fermanian, D.J. Wehner, and L.A. Spomer, Dep. of Horticulture, Univ of Illinois at Urbana-Champaign, Urbana, IL 61801. Contribution from the Dep. of Horticulture, Univ. of Illinois at Urbana-Champaign. This study was part of Project no. 65-267 of the Agric. Exp. Stn., Univ, of Illinois at Urbana-Champaign. Received 25 Feb. 1987. *Corresponding author.

Published in Agron. J. 80:108-113(1988).
Turf managers sometimes experience poor or early loss of control of targeted weeds even when the herbicides are applied at recommended rates. This may be attributed to herbicide concentration dropping below the threshold level for control before the weed season is over.

Many papers have discussed the effectiveness of preemergence herbicides (Johnson, 1976; Miller et al., 1978). DCPA, introduced in 1959, has been used in a wide range of crops including turf (Weed Science Society of America, 1983). Many studies have been conducted to examine the performance of DCPA under different cropping conditions, reporting effective suppression of annual weed germination by DCPA (Menges and Hubbard, 1970; Miller et al., 1978; Walker, 1978). However, inconsistent control in comparison to other preemergence herbicides was reported by Johnson (1976).

Various half-life values of DCPA in the soil have also been reported by several investigators (Roberts et al., 1978; Branham, 1983; Hurto et al., 1979; Walker, 1978). Those half-life values ranged from 13 to $295 \mathrm{~d}$ depending on the prevalent soil environment. The rapid and inconsistent degradation rate of DCPA requires reexamination of the factors affecting its fate in soil to maximize its effective use in turf.

The primary DCPA degradation mode is proposed to be microbial degradation (Hurto and Turgeon, 1979; Lewis et al., 1978; Fields et al., 1967). Many researchers have reported a relatively small contribution of volatilization, photochemical decomposition, leaching, adsorption, or uptake by plants to the dissipation of DCPA (Branham, 1983; Glofelty et al., 1984; Miller et al., 1978; Iyer et al., 1969). If microbial degradation is a major mechanism for the loss of DCPA activity in soil, factors such as soil temperature, soil moisture, and soil type affecting microbial activity would be important in understanding the rate of loss of DCPA.

Walker (1978) reported that soil temperature and soil moisture affected the degradation rate of eight different herbicides under controlled laboratory conditions. A general trend of faster degradation rates was observed with increasing soil temperature up to approximately that optimal for soil microbial activities 
$\left(30^{\circ} \mathrm{C}\right)$ and increasing soil moisture content (up to $12.6 \%$ by volume). Walker (1976) reported slightly faster degradation of propyzamide [3,5-dichloro- $(N-1,1-$ dimethyl-2-propynyl) benzamide] in sandy soil than in a heavier soil in an investigation of the effect of different soil textures on the degradation of propyzamide, a preemergence herbicide for weed control in lettuce (Lactuca sativa $\mathrm{L}$.).

The ability to predict preemergence herbicide degradation in turf is essential for herbicide optimal use. In this way, excessive pesticide applications would be avoided, a benefit from the standpoint of both economics and environmental quality. DCPA was chosen as a representative turfgrass herbicide for this study because it is used widely in turfgrass management operations and the methodology for its analysis in soil has been previously developed (Branham, 1983).

The objective of this study was to investigate the effect(s) of soil temperature, soil moisture, and soil texture on DCPA persistence applied at the labeled usage rate.

\section{MATERIALS AND METHODS}

Flanagan silt loam and fine sand were used in all experiments and selective properties are shown in Table 1. Bulk soil samples were air-dried in the laboratory $\left(20^{\circ} \mathrm{C}\right)$ and the large aggregates were disrupted with a mortar and pestle. Both the soil and sand were then passed through a wire mesh sieve with $1.7-\mathrm{mm}$ openings to remove the large particles.

Technical grade $(98.7 \%$, w/w) DCPA was used to formulate a $0.1 \%(\mathrm{w} / \mathrm{w})$ DCPA-soil mixture using a Buchler Flash Evaporator (Buchler Instruments Co., Ft. Lee, NJ). The large aggregates of dried DCPA-soil mixture were disrupted with a mortar and pestle until everything passed through an $0.85-\mathrm{mm}$ sieve. Each experimental unit consisted of $150 \mathrm{~g}$ of air-dried soil plus $5.04 \mathrm{~g}$ of the $0.1 \%$ DCPA-soil mixture in a $250-\mathrm{mL}$ Erlenmeyer flask. The final concentration of DCPA was $33 \mathrm{mg} \mathrm{kg}^{-1}$ of air-dried soil (equivalent to $11.8 \mathrm{~kg} \mathrm{DCPA} \mathrm{ha}^{-1}$ incorporated to a depth of $2.5 \mathrm{~cm}$ ).

\section{Temperature and Moisture Experiments}

Constant temperature chambers provided six different incubation temperatures $\left(10,15,20,25,30\right.$, and $\left.35^{\circ} \mathrm{C}\right)$. Each chamber consisted of a styrofoam enclosure ( 50 by 35 by 20 $\mathrm{cm}$ ) to minimize heat exchange, with ambient room temperature, physical sample support (hardware cloth rack), an exposed nichrome wire beneath the physical support, and a precise proportional temperature controller (Spomer, 1982; 1987). The six chambers were housed in a refrigerated room $\left(4^{\circ} \mathrm{C}\right)$, and the desired temperatures were obtained by heating the chamber above room temperature. Temperature treatments were not replicated. However, temperature within each chamber was monitored at 30-min intervals with a thermocouple data logger (Fluke model 2240B with model 2201A scanner chassis; John Fluke Manufacturing Company, Inc., Everett, WA). Little or no temperature fluctuation was observed (less than $\pm 1^{\circ} \mathrm{C}$ ).

Three replicates of three soil moisture concentrations were maintained gravimetrically in each temperature. These treatments consisted of adding enough deionized water to result

Table 1. Analysis of soil and sand used in the experiments.

\begin{tabular}{lcccrrrr}
\hline & $\mathrm{pH}$ & $\begin{array}{c}\text { Organic } \\
\text { matter }\end{array}$ & $\begin{array}{c}\text { Cation exchange } \\
\text { capacity }\end{array}$ & Sand & Silt & Clay \\
\hline & & $\%$ & $\mathrm{cmol}\left(1 / 2 \mathrm{Mg}^{2+}\right) \mathrm{kg}^{-1}$ & - & $\%$ & - \\
Flanagan silt loam & 6.9 & 3.4 & 20.4 & 18 & 58 & 24 \\
Sand & 7.5 & 0.2 & 7.7 & 100 & 0 & 0 \\
\hline
\end{tabular}

in $0.4 \mathrm{~kg} \mathrm{H}_{2} \mathrm{O} \mathrm{kg}^{-1}$ soil, high (-0.01 MPa); $0.2 \mathrm{~kg} \mathrm{H}_{2} \mathrm{O} \mathrm{kg}^{-1}$ soil, medium ( $-0.1 \mathrm{MPa})$; and $0.1 \mathrm{~kg} \mathrm{H}_{2} \mathrm{O} \mathrm{kg} \mathrm{kg}^{-1}$ soil, low $(-1.32 \mathrm{MPa})$ soil water content (water potentials). Subsequent evaporation was minimized by plugging the opening of the flask with a cotton stopper that allowed sufficient $\mathrm{O}_{2}$ and $\mathrm{CO}_{2}$ exchange. Water loss was monitored at 3- to 4-d intervals by weighing, and deionized water was added as needed to maintain the soil moisture levels. The soil was mixed following every water addition to promote uniform distribution within the flask. Ten grams of treated soil were sampled each week for $8 \mathrm{wk}$. Samples were stored at $-10^{\circ} \mathrm{C}$ until they were analyzed.

\section{Soil Texture Experiment}

Three replications of three different sand and soil mixtures were provided by mixing autoclaved $\left(120^{\circ} \mathrm{C}\right.$ at $0.12 \mathrm{MPa}$ for $20 \mathrm{~min}$ ) sand and Flanagan silt loam soil. The preparation of three (fine, medium, and coarse) soil texture treatments and their pH after autoclaving are shown in Table 2. A small amount of nonautoclaved soil $\left(50 \mathrm{~g} \mathrm{~kg}^{-1}\right)$ was added to incorporate microorganisms. This experiment was conducted at $20^{\circ} \mathrm{C}$ as the results of the temperature experiment indicated that $20^{\circ} \mathrm{C}$ was close to the optimum temperature for the degradation of DCPA in Flanagan silt loam soil. Different soil moisture contents were maintained at 0.21 , $0.16,0.14 \mathrm{~kg}$ deionized water per kilogram of each of the fine, medium, and coarse textured soils (approximate water potentials of $-0.09,-0.05$, and $-0.01 \mathrm{MPa}$, respectively). All soil moisture treatments selected were within the range for which degradation rates were not observed to be significantly different in the previous experiment.

\section{DCPA Extraction}

The method of Branham (1983) was used for DCPA extraction from the soil. Briefly, DCPA in soil samples $(10 \mathrm{~g})$ was extracted in $50 \mathrm{~mL}$ of acidified acetone $(95: 25: 2.5$, acetone/sulfuric acid/deionized water, $v / v$ ) for $2 \mathrm{~h}$ with a wristaction shaker. Whatman \# 1 filter paper (Whatman Inc., Clifton, NJ) was used to filter out the soil followed by two subsequent rinses of the soil slurry with $15 \mathrm{~mL}$ of acidified acetone. The solvent was evaporated until a final volume of 5 to $7 \mathrm{~mL}$ remained. This was mixed with $50 \mathrm{~mL}$ of $0.4 \mathrm{M}$ $\mathrm{NaHCO}_{3}$ and then transferred to a $250-\mathrm{mL}$ separatory funnel. Three $40-\mathrm{mL}$ portions of isopropyl ether were then used to extract the DCPA. The ether extracts were mixed with $0.2 \mathrm{~mL}$ of $2 \%$ paraffin oil in benzene to prevent DCPA loss by volatilization. The ether was evaporated by passing an air stream over the extract. Three milliliters of $100 \%$ methanol (high performance liquid chromatography grade) was added and then filtered through $0.22 \mu \mathrm{m}$ Millipore filters (type GS; Millipore Corp., Milford, MA). The average extraction efficiency was $95.5 \%$. The solution was placed in a 1 -mL serum vial with a cap and stored until analysis.

High Performance Liquid Chromatography Analysis

An ultrasphere-IP column (150 by $4.6 \mathrm{~mm}$ ) was used in a high performance liquid chromatography system (HPLC) consisting of Beckman model $100 \mathrm{~A}$ and 110 pumps, model

Table 2. Preparation of the three soil texture treatments.

\begin{tabular}{|c|c|c|c|c|}
\hline \multirow[b]{2}{*}{ Soil treatment } & \multirow[b]{2}{*}{$\mathrm{pH} \dagger$} & \multicolumn{2}{|c|}{ Autoclaved } & \multirow{2}{*}{$\begin{array}{l}\text { Nonautoclaved } \\
\text { silt loam }\end{array}$} \\
\hline & & Sand & Silt loam & \\
\hline & & & to by weigh & - \\
\hline $\begin{array}{l}\text { Fine } \\
\text { Medium } \\
\text { Coarse }\end{array}$ & $\begin{array}{l}6.1 \\
6.6 \\
7.2\end{array}$ & $\begin{array}{l}47.5 \\
95\end{array}$ & $\begin{array}{l}95 \\
47.5\end{array}$ & $\begin{array}{l}5 \\
5 \\
5\end{array}$ \\
\hline
\end{tabular}

$\uparrow$ After sterilization. 


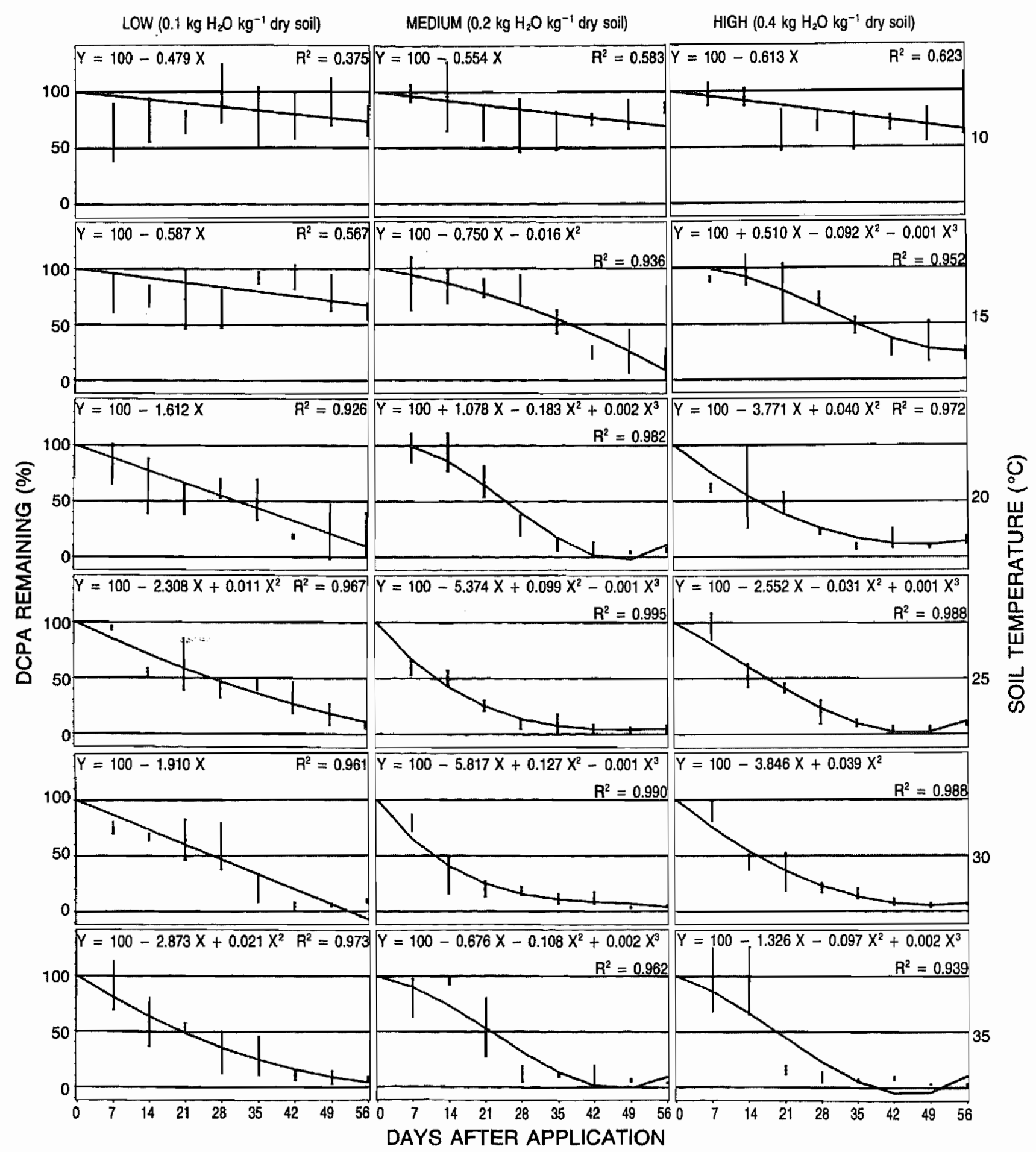

Fig. 1. The degradation rate of DCPA over a 56-d period in a Flanagan silt loam, as influenced by six soil temperatures and three soil moisture levels. Each data point represents the mean of three replications; bars indicate \pm SD.

421 system controller, model 500 automatic sample injector (Beckman Instruments, Fullerton, CA), model 155-10 Hitachi UV-visible spectrophotometer (NSA Hitachi, Nissei Sangyo Co., Ltd., Mountain View, CA), and Shimadzu model CR-IA integrating recorder (Shimadzu Scientific Instruments Inc., Columbia, $M D)$. A $15-\mathrm{cm}$ by $4.6-\mathrm{mm}$ analytical column was packed with $5 \mu \mathrm{m}$ of octadecylsilane material (reversed phase C-18). A 45 - by 46-mm precolumn (ultrasphere-IP) was used to protect the analytical column.

The mobile phase consisted of methanol and water $(75: 25$, $\mathrm{CH}_{3} \mathrm{OH} / \mathrm{H}_{2} \mathrm{O}, \mathrm{v} / \mathrm{v}$ ). The flow rate was programmed for 1.5 $\mathrm{mL} \mathrm{min}^{-1}$ for $5.3 \mathrm{~min}$, then decreased to $1.0 \mathrm{~mL} \mathrm{~min}^{-1}$. DCPA was eluted with a retention time of $8.4 \mathrm{~min}$.

Data collected from HPLC analysis of DCPA concentra- 
Table 3. Predicted half-life of DCPA for six soil temperatures and three soil moisture levels in a Flanagan silt loam.

\begin{tabular}{|c|c|c|c|c|c|c|c|c|}
\hline \multirow{3}{*}{$\begin{array}{c}\text { Soil } \\
\text { temperature }\end{array}$} & \multicolumn{8}{|c|}{ Soil moisture level } \\
\hline & \multicolumn{2}{|c|}{$\begin{array}{c}\text { Low } \\
\left(0.1 \mathrm{~kg} \mathrm{H}_{2} \mathrm{O} \mathrm{kg}^{-1} \text { soil) }\right.\end{array}$} & \multicolumn{2}{|c|}{$\begin{array}{c}\text { Medium } \\
10.2 \mathrm{~kg} \mathrm{H}_{2} \mathrm{O} \mathrm{kg}{ }^{-1} \text { soill } \\
\end{array}$} & \multicolumn{2}{|c|}{$\begin{array}{c}\text { High } \\
\left(0.4 \mathrm{~kg} \mathrm{H} \mathrm{H}_{2} \mathrm{~kg}^{-1} \text { soil) }\right. \\
\end{array}$} & \multicolumn{2}{|c|}{ Average } \\
\hline & Eq. $[1] \dagger$ & Eq. [2]‡ & Eq. [1] & Eq. [2] & Eq. [1] & Eq. [2] & Eq. [1] & Eq. [2] \\
\hline${ }^{\circ} \mathrm{C}$ & 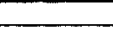 & 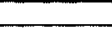 & $\ldots$ & 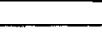 & - & & & \\
\hline $\begin{array}{l}10 \\
15 \\
20 \\
25 \\
30 \\
35\end{array}$ & $\begin{array}{r}105 \\
85 \\
31 \\
26 \\
26 \\
21\end{array}$ & $\begin{array}{l}71 \\
51 \\
36 \\
28 \\
26 \\
29\end{array}$ & $\begin{array}{l}\mathbf{9 0} \\
37 \\
23 \\
11 \\
11 \\
\mathbf{2 4}\end{array}$ & $\begin{array}{l}62 \\
41 \\
27 \\
19 \\
16 \\
20\end{array}$ & $\begin{array}{l}82 \\
34 \\
16 \\
18 \\
15 \\
20\end{array}$ & $\begin{array}{l}64 \\
44 \\
29 \\
21 \\
19 \\
22\end{array}$ & $\begin{array}{l}92 \\
52 \\
24 \\
18 \\
18 \\
22\end{array}$ & $\begin{array}{l}66 \\
45 \\
31 \\
29 \\
20 \\
24\end{array}$ \\
\hline Average & 49 & 40 & 32 & 31 & 30 & 33 & & \\
\hline
\end{tabular}

† Half-life calculated from the corresponding regression equation (Fig. 1) when $y=50$; where $y$ is DCPA remaining (\%) and $x$ is days after application. $\ddagger$ Half-life $=54.2-20\left(-11.07+0.707 \mathrm{ST}-0.012 \mathrm{ST}^{2}+0.198 \mathrm{SM}-0.0035 \mathrm{SM}^{2}\right)^{1 / 2}$.

tion were converted to percent DCPA remaining after correcting for the extraction efficiency. For each soil temperature and soil moisture combination, and for each soil texture, percent DCPA remaining was regressed with time in days.

\section{RESULTS AND DISCUSSION}

\section{Soil Temperature Effect}

DCPA degradation patterns for each soil temperature and soil moisture combination are shown in Fig. 1 . All the regression models were highly significant $(P=0.01)$. Soil maintained at 10 or $15^{\circ} \mathrm{C}$ and at low soil moisture resulted in the very slow loss of DCPA. The rate of DCPA degradation increased as soil temperature was increased up to a maximum at 25 and $30^{\circ} \mathrm{C}$, after which it placated or decreased. Since the major route for DCPA degradation is thought to be through microbial decomposition (Walker, 1978), the soil temperatures optimal for soil microorganism growth (between 25 and $30^{\circ} \mathrm{C}$ ) should cause the fastest degradation of DCPA.

\section{Soil Moisture Effect}

Soil moisture also influenced the rate of DCPA degradation. The driest soil treatment (low) reduced degradation below the medium and high treatments, which had about the same effect (Table 3 ). These results agree with Walker's finding of increased DCPA persistence with decreased soil moisture content (1978).

The lack of a significant difference in degradation rates between medium and high soil moisture content may indicate that the medium soil moisture level was above or close to the threshold level necessary to support an optimum population of DCPA degrading microorganisms. This is in agreement with the study by Obrigawitch et al. (1982) in which no significantly different rates of EPTC ( $S$-ethyl dipropylthiocarbamate) degradation were observed when the soil moisture was higher than $3 \%$. Similar results were observed from the degradation of atrazine (2-chloro-4-ethylamino-6isopropylamino-s-triazine) by Hurle and Kibler (1976). The half-life values of atrazine at 9 and $7 \%$ soil moisture contents were 37 and $36 \mathrm{~d}$, respectively, while a half-life of $151 \mathrm{~d}$ occurred at $0.8 \%$ soil moisture.

The results from the first experiment were pooled and used to develop a model of DCPA loss to deter- mine the relative contribution of time, soil moisture, and soil temperature to the rate of degradation. The model (Eq. [1]) had a $R^{2}$ value of $0.738(P<0.001)$. Partial $R^{2}$ values for each factor were $0.515,0.207$, and 0.016 for time, soil temperature, and soil moisture, respectively. Percent DCPA remaining was estimated by the equation

$\%$ DCPA $=214.90-2.71 \mathrm{TI}+0.025 \mathrm{TI}^{2}$

$-7.07 \mathrm{ST}+0.12 \mathrm{ST}^{2}-1.98 \mathrm{SM}+0.03 \mathrm{SM}^{2}$

where TI is time in days, $\mathrm{ST}$ is soil temperature in ${ }^{\circ} \mathrm{C}$, and $S M$ is soil moisture in percentage $(w / w)$. It may be inferred from the model that time is the most important factor in determining the rate of DCPA degradation. Soil temperature contributes more to the rate of DCPA degradation than does soil moisture content.

Dominance of soil temperature over soil moisture in this model may be the result of several factors. Kowalenko et al. (1978) investigated the effect of moisture content and temperature along with $\mathrm{N}$ fertilization on $\mathrm{CO}_{2}$ evolution from field soil. In that study, temperature effects $(r=0.67)$ were more dominant than moisture effects $(r=-0.28)$. The researchers thought "the effect of water content was complex and dependent on whether it is above or below the optimum water content."

Walker (1978) reported a strong temperature dependence of DCPA among eight herbicides. The halflife of DCPA decreased by a factor of 17.9 when soil temperature increased from 10 to $30^{\circ} \mathrm{C}$ and moisture content increased from 9 to $11 \%$, whereas the half-life of linuron [3-(3,4-dichlorophenyl)-1-methoxy-1-methylurea] decreased by a factor of 2.3 under the same conditions.

Possible reasons for temperature dominance in this study are: (i) DCPA degradation may have a characteristic temperature dependence; (ii) two of the three soil moisture levels might exceed the optimum for microbiological activity; (iii) other unknown factors. A combination of two or more factors is likely involved in the dominance of temperature in this study.

Equation [1] was modified to express the half-life of DCPA (time) as a dependent variable, and soil temperature and soil moisture as independent variables (Eq. [2]). This permits the estimate of the half-life of DCPA by substituting soil temperature and soil mois- 


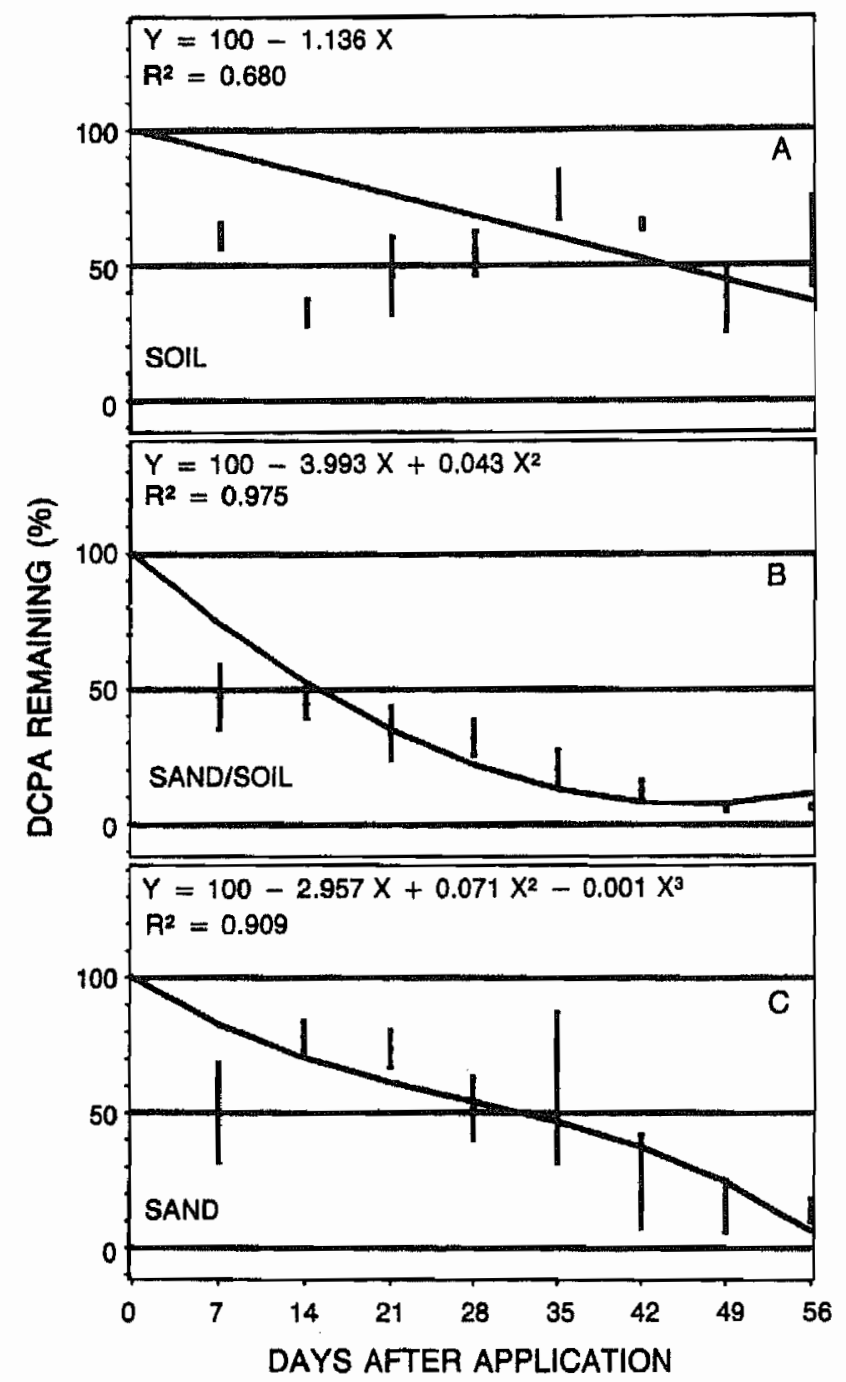

Fig. 2. The degradation rate of DCPA over a 56-d period, as influenced by three different soil textures. Each data point represents the mean of three replications.; bars indicate \pm SD.

ture for any soil temperature and moisture within the range of the soil temperatures and soil moistures examined for each soil type.

$\begin{aligned} \text { Half-life }= & 54.2-20\left(-11.07+0.707 \mathrm{ST}-0.012 \mathrm{ST}^{2}\right. \\ & \left.+0.198 \mathrm{SM}-0.0035 \mathrm{SM}^{2}\right)^{1 / 2}\end{aligned}$

The time required for $50 \%$ disappearance of DCPA was estimated using (i) the individual regressing equations shown in Fig. 1, and (ii) the generalized model (Eq. [2]). The range of estimated half-life was narrower from the generalized model than from corresponding regression equations. The shortest half-life $(11 \mathrm{~d})$ was predicted when DCPA was applied to soil at either 25 or $30^{\circ} \mathrm{C}$ at the medium soil moisture level. The shortest half-life would indicate that in less than 3 wk approximately $75 \%$ of the DCPA would be lost in the field when the soil temperature is above $25^{\circ} \mathrm{C}$ and the soil moisture is adequate. A half-life of $105 \mathrm{~d}$ was predicted for the low temperature of $10^{\circ} \mathrm{C}$ with a low soil moisture level.

Soil temperature and moisture conditions from other studies were used to test the fitness of the generalized model. Walker (1978) reported $40.5 \mathrm{~d}$ (half-life of DCPA) from $20^{\circ} \mathrm{C}$ (soil temperature) and $12.2 \%$ (soil moisture), while the current model estimated $46 \mathrm{~d}$ for the same condition. Another close estimation was observed from the study by Hurto et al. (1979). Twentyfive days were predicted by using the generalized model, while Hurto et al. (1979) reported $28 \mathrm{~d}$ for the conditions of $28^{\circ} \mathrm{C}$ (soil temperature) and $30 \%$ (soil moisture).

This close estimation was not observed from Branham's study (Branham, 1983). The average temperature in the model ecosystem chamber used in that study, with live turf was $20^{\circ} \mathrm{C}$, and the soil moisture content of the soil (irrigated every fourth day) was assumed to be about 20\%. A half-life (Eq. [2]) of $27 \mathrm{~d}$ was estimated from the current model in this study, while Branham (1983) observed the shortest half-life of about $50 \mathrm{~d}$ from the turf on a sandy soil with thatch. This difference was probably due to differences in a soil environment and a living system (turf) that exhibited a slower DCPA decomposition rate.

\section{Soil Texture Effect}

The effect of soil texture on the rate of DCPA degradation is illustrated in Fig. 2. The fastest degradation rate was observed in the medium soil texture. The halflife values of DCPA (Eq.[1]) for coarse, medium, and fine soil textures were 44,15 , and $32 \mathrm{~d}$ respectively.

A similar observation with napropamide [2-( $\alpha$-naphthoxy)- $N, N$-diethylpropionamide] was made by Walker et al. (1985). They found a significant correlation $(r=0.728)$ between clay content and the halflife of napropamide, and a highly significant correlation ( $r=0.843)$ between clay content and the adsorption distribution coefficient.

There has been little direct research on the effect of soil types on the DCPA degradation. However, many reports on the minimal movement of DCPA in the soil profile suggest that there may be a high chance of DCPA adsorption to soil, particularly organic matter or clay (Hurto and Turgeon, 1979; Mazur et al., 1969; Menges and Hubbard, 1970; Miller et al., 1978). If we assume high adsorption of DCPA to clay, a slower degradation rate can be expected from a soil with a higher clay content, leaving DCPA less available for microorganism decomposition. This might explain the more rapid dissipation of DCPA in the medium soil texture than in the fine soil texture. Since the coarse soil texture did not contain appreciable amounts of clay, it may not have responded in a similar manner.

In Fig. $2 \mathrm{~A}$, data from the first 2 to 3 wk does not seem to fit the regression line well. A quadratic or cubic term was not included in the equation to avoid confusion in representing fluctuating DCPA residuals. The first two to three readings were probably reduced by some artifact of the DCPA extraction procedure.

The ability to predict preemergence herbicide degradation in soil under turf should result in optimizing its use. This predictive ability would be beneficial, both economically and environmentally. Prediction of the best timing of a second application and the minimum rate required to maintain effective weed control could save on material and possibly labor, and provide better overall weed control. Reducing the rate of a second or third application would reduce the total quantity of DCPA added to the environment. From the point of environmental contamination, even though no se- 
rious carry-over effects of DCPA are known, it would be best for the ecosystem to keep the amount of DCPA application low as long as weed control goals could be accomplished.

\section{SUMMARY AND CONCLUSION}

Soil temperature, soil moisture, and soil texture each influenced the persistence of DCPA. Even though the effects of these factors were likely indirect, their correlation with DCPA dissipation was very high. When an optimum environment $\left(25\right.$ to $30^{\circ} \mathrm{C}$, soil temperature; $0.2 \mathrm{~kg} \mathrm{H}_{2} \mathrm{O} \mathrm{kg} \mathrm{kg}^{-1}$ soil, soil moisture) for breakdown was provided, very fast degradation was observed (half-life of $11 \mathrm{~d}$ ), while $105 \mathrm{~d}$ was estimated for the loss of half the initial concentration under the unfavorable condition of $10^{\circ} \mathrm{C}$ soil temperature and low soil moisture.

The objective of this study was to achieve the ability to predict when one half of the initial concentration of DCPA would be lost. Predictions made from the result of laboratory studies often do not carry over directly to a field situation. Further studies are needed to test the predictability of the model from the laboratory study for use in the field and to compensate for any lack of fit if necessary.

We can safely conclude, however, that degradation of DCPA is largely dependent on the condition of the soil environment including soil temperature, soil moisture, and soil texture. Since the soil environment varies greatly throughout the year and over different locations, the period of effective DCPA concentration in the soil will not be constant. This might be an explanation for the inconsistency of weed control by DCPA in the soil. Thus it is suggested that soil environmental factors be considered in determining the timing of second or subsequent applications when necessary, rather than following a fixed application schedule.

\section{ACKNOWLEDGMENTS}

The authors wish to thank Drs. W. Banwart, B. E. Branham, M. A. Cole, and H. T. Wilkinson for their suggestions and their assistance with this project.

\section{REFERENCES}

Branham, B.E. 1983. The fate of DCPA and diazinon in turf using model ecosystems. Ph.D. diss. Univ. of Illinois, Urbana (Diss. Abstr. 83-24513)

Fields, M.L., R. Der, and D.O. Hemphill. 1967. Influence of DCPA on selected soil microorganisms. Weeds 15:195-197.

Glofelty, D.E., A.W. Taylor, B.C. Turner, and W.H. Zoller. 1984. Volatilization of surface-applied pesticides in fallow soil. J. Agric. Food Chem. 23:638-643.

Hurle, K., and E. Kibler. 1976. The effect of changing moisture conditions on the degradation of atrazine in soil. Proc. Br. Crop Prot. Conf. Weeds: 627-633.

Hurto, K.A., and A.J. Turgeon. 1979. Influence of thatch on preemergence herbicidal activity in Kentucky bluegrass (Poa pratensis) turf. Weed Sci. 27:141-146.

, and M.A. Cole. 1979. Degradation of benefin and DCPA in thatch and soil from a Kentucky bluegrass (Poa pratensis) turf. Weed Sci. 27:154-157

Iyer, F.G., G. Chesters, and S.A. Wilde. 1969. Chlorthal degradation in soils and its uptake by pine seedlings. Weed Res. 9:53-61.

Johnson, B.J. 1976. Herbicides for seasonal weed control in turfgrasses. Agron. J. 68:717-720.

Kowalenko, C.G., K.C. Ivarson, and D.R. Cameron. 1978. Effect of moisture content, temperature and nitrogen fertilization on carbon dioxide evolution from field soils. Soil Biol. Biochem. 10:417423.

Lewis, J.A., G.C. Paparizas, and T.S. Hora. 1978. Effect of some herbicides on microbial activity in soil. Soil Biol. Biochem. 10:137141.

Mazur, A.R., J.A. Jagschitz, and C.R. Skogley. 1969. Bioassay for bensulide, DCPA and siduron in turfgrass. Weed Sci. 17:31-34.

Menges, R.M., and J.L. Hubbard. 1970. Selectivity, movement and persistence of soil-incorporated herbicides in carrot plantings. Weed Sci. 18:247-252.

Miller, J.H., P.E. Keeley, R.J. Thulien, and C.H. Carter. 1978. Persistence and movement of ten herbicides in soil. Weed Sci. 26:2027.

Obrigawitch, T., R.G. Wilson, A.R. Martin, and F.W. Roeth. 1982. The influence of temperature, moisture, and prior EPTC application on the degradation of EPTC in soils. Weed Sci. 30:175181 .

Roberts, H.A., A. Walker, and W. Bond. 1978. Persistence of chlorthal-dimethyl activity in soil. Proc. Br. Crop Prot. Conf. Weeds: $87-92$.

Spomer, L.A. 1982. A simple, inexpensive proportional water-bath temperature controller. J. Phys. 15:1163-1164.

- 1987. A simple, inexpensive, precise temperature control chamber. HortScience 22:138-140.

Walker, A. 1976. Simulation of herbicide persistence in soil. I Simazine and prometryne. Pestic. Sci. 7:41-49.

1978. Simulation of the persistence of eight soil applied herbicides. Weed Res. 18:305-313.

, P.A. Brown, and P.R. Mathews. 1985. Persistence and phytotoxicity of napropamide residues in soil. Ann. Appl. Biol. 106:323-333

Weed Science Society of America. 1983. Herbicide handbook of the Weed Science Society of America. 5th ed. Champaign, IL. 